\title{
Exploring the unique contributions of nurses from different cultural groups in South Africa
}

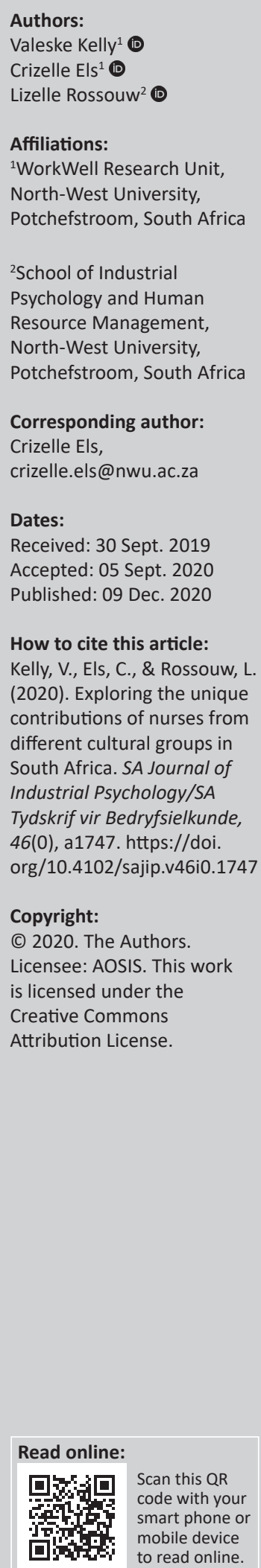

Orientation: Diverse backgrounds often become the basis for conflict, separation and mistrust in the workplace. The unique quality that each culture contributes to the workplace is often misjudged as differences or annoying habits.

Research purpose: The aim of this study was to explore the unique contributions of different cultural groups in the workplace.

Motivation for the study: One cannot appreciate diversity if one does not know what there is to appreciate. Empirical research regarding the unique contributions of different cultural groups in South Africa is lacking.

Research approach/design and method: A qualitative descriptive design was followed. The sample comprised of nurses $(N=17)$ from two hospitals within the North West Province. The data were collected by means of semi-structured interviews.

Main findings: The participants did not have a clear understanding of what constitutes culture. Most participants were unaware of the unique contributions their colleagues from different cultures can offer to the workplace. The vast majority of participants expressed a need for cultural training in an attempt to improve colleague relationships and to foster an appreciation for cultural contributions.

Practical/managerial implications: Participants do not have a clear understanding of what unique contributions different cultures bring to the workplace. This is alarming and poses great threats for the effective management of diversity.

Contribution/value-add: This study identifies a lack of appreciation for cultures as one explanation for poor diversity management. This study highlights the need for training and other diversity initiatives to foster an appreciation for diversity.

Keywords: diversity; cultural diversity; appreciation of diversity; culture; nurses.

\section{Introduction}

\section{Orientation}

South Africa, often referred to as the 'rainbow nation', is known for its diversity. With 11 official languages, it is home to a fascinating mix of citizens, all of them with unique features to distinguish them. Optimising, maintaining and absorbing the full potential of such a multicultural group of employees in all organisations across South Africa remains one of the core challenges for organisations (Cilliers, 2007).

Research has shown that diversity in the workplace can have a competitive advantage if managed correctly, but diversity by itself cannot lead to a competitive edge (Pretorius, Cilliers, \& May, 2012). According to Human (2005), because of the complex nature of diversity, if not competently managed, it can lead to extreme implications for organisations. These implications typically have costs involved in terms of decreased production, ineffective communication, absenteeism, insignificant use of resources, lack of commitment and low morale (Human, 2005; Pretorius et al., 2012). It is, therefore, crucial that organisations start gaining a competitive advantage by managing diversity effectively and thereby reaping the benefits, instead of constantly undergoing misfortunes or success hindrances as a result of poor diversity management.

Therefore, it is clear that strategies need to be in place to foster a working environment where diversity is appreciated. This is especially true within the South African context where we have an extremely diverse workforce. However, it seems as if the diversity we face in South Africa is still 
seen by many as a threat, rather than the opportunity that it really could be if managed correctly. According to Pretorius et al. (2012), there is a great need to gain a deeper understanding of diversity, and this understanding and awareness can only develop if organisations take the unconcealed (overt) and the concealed (covert) behavioural dynamics of diversity into consideration. By viewing cultural diversity in an explorative and dynamic manner to gain a more comprehensive understanding would help organisations in managing diversity more effectively, which would, in turn, lead to employee engagement (Coetzee, 2016). However, the question remains as to how an organisation can take advantage of the unique contributions of the employees from culturally diverse backgrounds if there is a lack of knowledge regarding these possible contributions from their employees. The potential value-add of this research, therefore, is to create an awareness of the existence of unique cultural dynamics between work groups and how these different cultural groups can bring their own unique contributions to the workplace to enhance effectiveness. Such an awareness of the unique contributions of diverse employees may result in an appreciation for the uniqueness of each cultural group and the contributions they can bring to the workplace.

\section{Research purpose and objectives}

The general objective was to explore the unique contributions of different cultural groups within the nursing environment in South Africa. The specific objectives were to: (1) explore the unique contributions individuals believe their own cultural group can bring to the organisation; (2) investigate what, according to one cultural group, another cultural group can contribute to the organisation; and (3) investigate whether an awareness of the unique contributions of individuals from different cultural groups would increase the appreciation of diversity in the workplace.

\section{Literature review}

\section{Diversity and diversity management}

Diversity has many operational definitions that make the existing literature on it confusing (Cilliers, 2007). The multifaceted definition of diversity, as proposed by Williams and O'Reilly (1998, p. 81), states that diversity is 'any attribute that another person may use to detect individual differences'. Specifically, cultural diversity can be described as the affiliation of people in a social system with different group associations and may also form cultural identities in which people with a membership to a group share certain values, norms and traditions (Cox, 1994). Because these values, attributes and behaviours of one's cultural identity develop over time, it is bound to influence one's behaviour, which is often associated with conflict between diverse others (Jackson, Joshi, \& Erhardt, 2003). This conflict in the workplace can be minimised by effective diversity management initiatives.

Diversity management aims to improve the effectiveness and well-being of an organisation by sustaining a value and respect for human differences, social righteousness, pro-action, humility, authenticity, community, social participation, effectiveness and learning (Cilliers, 2007; Human, 2005). By viewing diversity as an opportunity, it creates a space in the organisation for positive organisational change (Cooperrider \& Sekerka, 2006) with beneficial properties such as improved productivity, creativity, work quality, commitment, trust and overall satisfaction (e.g. Spreitzer, Sutcliffe, Dutton, Sonenshein, \& Grant, 2005; Stevens, Plaut, \& Sanchez-Burks, 2008). According to De Beer (2016), the strength of a work team can lie in its rich diversity, because diverse teams face more challenges in aligning their goals, establishing trust and relationships, communicating priorities, making decisions together and implementing actions. Diversity in teams within an organisation will surely assist employees in developing flexibility, improving negotiating skills, developing an open mind and ensuring continuous learning. By optimising the strengths that diversity brings about, nurses in hospitals would be able to work together in making complex decisions where varied interests are brought to the table, allowing for new knowledge to be developed (Gardner, 2005).

The South African government has acknowledged the fact that diversity is important, and as a result, legal requirements pertaining to diversity in South Africa have been put in place and are a good indication of the readiness of the government to address diversity management for improving social and economic spectrum in South Africa (Ocholla, 2002). Consequently, South African organisations also became aware of the differences between employees and how these can cause intense emotions and conflict if not dealt with correctly (Pretorius et al., 2012). Many diversity programmes were designed and presented with the objective of creating opportunities for everyone in the South African 'rainbow nation' as a way of celebrating diversity (Thompson, 2001). Furthermore, legislation on employment equity and affirmative action brought in a form of co-operation with organisations for emotional and economic survival (Cilliers \& Stone, 2005).

However, some traditional approaches to diversity management, up until today, tend to focus more on facilitating an awareness of differences and ensuring that nondiscriminative policies are in place and adhered to, rather than focusing on attitudinal and behavioural change at individual level (Pretorius et al., 2012). These approaches to diversity implemented in organisations often fail because of a poor understanding of the underlying behavioural dynamics of cultural diversity such as cognitive understanding and emotional intelligence (understanding emotions; Watts, 2009). Consequently, the need is to obtain a deeper and thorough understanding of cultural diversity and how the differences and similarities between cultural groups in the workplace can contribute to an all-inclusive multicultural workplace. 


\section{Cultural awareness and appreciation of diversity in the nursing environment}

It is inevitable that people from all organisational domains have to continuously acquire new knowledge and practices to function well in a fast-changing multicultural world. The same holds true for the nursing environment where nurses are expected to provide 'culturally congruent care' (Leininger, 2002). Leininger (2002) proposed that nurses need to have the ability to provide comprehensive care in a variety of ways that match a variety of different cultures, needs and situations. The cultural care theory, focused specifically on nurses, suggests that nurses need an in-depth knowledge of culture because the caretaking of patients has different meanings within diverse cultural contexts (Leininger, 2002). Thus, nurses have to be sensitive towards the cultures of their patients and attentive to the way in which they take care of the culturally different. People working with diverse others in some cases show lower commitment to the organisation, less satisfaction, perceive more discrimination and show a variety of other negative behaviours and attitudes (Jayne \& Dipboye, 2004). It is unavoidable that diversity is complex and that positive outcomes can only come to the fore when the culturally diverse workforce is managed effectively, including revising current rules and regulations (Zulu \& Parumasur, 2009). The same holds true for the nursing environment where nurses are expected to work closely together with their colleagues when caring for patients. Therefore, building relationships to encourage support amongst nurses working together is essential.

Research indicated that nurses find affirming communication amongst each other, such as the acknowledgement and understanding of ideas and efforts, extremely important (Gardner, 2005). It can, therefore, be argued that nurses can strengthen their collaboration with each other by learning more about the different cultural groups of their fellow nurses, as well as the differences in their communication repertoire (Gardner, 2005). By learning about cultural differences and how these can be used to their full beneficial potential, it will inspire individuals to form high-quality relationships between diverse others and integrate an appreciation of diversity in their work life and personal life (Stevens et al., 2008). The formation of high-quality relationships will ultimately form the foundation in developing an all-inclusive multicultural work environment (Davidson \& James, 2006). In this all-inclusive multicultural environment, the appreciation of differences will ultimately be the key to better work relationships. Encouraging this approach towards cultural diversity in the workplace is a way of decreasing conflict and resistance by allowing all to feel respected and included in the organisation (Stevens et al., 2008). If employees feel valued, included and respected, organisational commitment, trust, internal motivation and satisfaction will serve as the backdrop against which employees interact with each other and in which everyday business will be conducted (Stevens et al., 2008).
The concept of ethnocentrism and the social identity theory provide theoretical frameworks to understand why people may find it difficult to embrace cultural diversity. The social identity theory holds the basic assumption that people identify themselves with a group of people who are similar to themselves (i.e. in-group) to form identity groups in order to reduce the anxiety that stems from diversity and the fear of the unknown (Coetzee, 2015). This results in a person favouring the in-group and often discriminating against groups other than their own (i.e. out-group; Tajfel \& Turner, 1986). This is often the root of stereotyping, projection and bias that may result in conflict between identity groups (Coetzee, 2016), and this may be one of the main reasons why people do not recognise the positive contributions that people from other groups can offer to the organisation. However, Coetzee (2007) explains that by starting to appreciate diversity and crossing the boundaries of identity groups, people will start to explore the similarities and gain an understanding of the differences between groups. This may ultimately enable people from different groups to develop a better understanding and trust for one another (Coetzee, 2007). When people start getting acquainted with each other, learning and asking open questions about groups other than their own, they form a sense of compassion for people from other groups, which leads to a desire to include everyone in a group - whether social or in a work environment (Coetzee \& Cilliers, 2012).

Research on the concept of ethnocentrism similarly explains that ethnocentrism is the assumption that one's own culture and way of life are superior to all others and belief that all unfamiliar cultural characteristics are inferior when compared to the in-group's values (Mounsey, 2007). Symbols and artefacts of the in-group are seen as objects of pride, whereas out-group's cultural symbols trigger hatred and negativity (Mounsey, 2007). Ethnocentrism, in some cases, can lead to discrimination, interpersonal conflict and the deliberate destruction of a group different from one's own (Thompson \& Cuseo, 2009).

To conclude, an organisation can only foster a culture where diversity is appreciated if the organisation becomes aware of the unique contributions that people from different cultural groups can add to the workplace. Cultural relativity is a newly presented term that suggests that even though members from different cultural groups have different backgrounds, values, beliefs and other differences, they are equally valued and worthy of respect (Thompson \& Cuseo, 2009). When an organisation comes to terms with this and fosters a climate where cultural differences are valued and respected, it will be an organisation well on its way to appreciate cultural diversity.

\section{Research design Research approach and strategy}

This study followed a qualitative research design, following an inductive, descriptive approach. 
Specifically, a qualitative descriptive research strategy was used. The purpose of qualitative description is to provide descriptions of phenomena in their natural state and is typically used in studies where the researcher aims to describe the who, what and where of an event or experience (Sandelowski, 2000).

\section{Research method}

\section{Research setting}

The study was conducted amongst nurses who are actively involved in patient care at two hospitals within the North West Province in South Africa. The interviews were conducted individually, in a private office that was at the disposal of the researchers, with a time that was convenient to the participants' schedules.

\section{Entrée and establishing researcher roles}

Access to the participants was granted by the superintendent of the hospitals, and after potential participants had expressed their willingness to participate, the researchers arranged for an interview date, time and location. The role of the researchers during the interview process was that of the interviewer. After the interviewing phase had been completed, the researchers took on the role of data analysts and report writers.

\section{Research participants and sampling methods}

A purposive, volunteer sampling method was utilised in this research. The sample of this study comprised female nurses from different ethnic and language groups in the North West Province who were actively involved in the caretaking of patients $(N=17)$. On the day of the data collection, the nurses from the participating hospitals who matched the purpose and criteria for the research project were informed of the study by the hospital manager. Those who were willing to participate in the study were requested to contact the researcher and an interview time was scheduled with these nurses. Thus, a volunteer sample was drawn from the study population. The composition of the sample is presented in Table 1.

As seen in Table 1, the sample consisted of 17 nurses from two hospitals. The youngest participant was 25 years and the oldest participant was 64 years. Most of the participants were white Afrikaans speaking, followed by black Setswana, black isiXhosa and only one mixed race English participant. Although not equally represented, the numbers reflect the ratio of staff according to cultural group. The majority of participants were registered nurses and enrolled nurses.

\section{Data collection methods}

The participants were informed about the nature and intention of the research project, and the reasons for the interest in this phenomenon were explained to them. Participants were given an informed consent form explaining that the participation in the study was completely voluntary and that they could withdraw at any given moment.

\begin{tabular}{llc}
\multicolumn{2}{l}{ TABLE 1: Profile of participants $(N=17)}$. & Frequency \\
\hline Item & Category & 3 \\
\hline Age & $25-30$ years & 5 \\
& $31-40$ years & 3 \\
& $41-50$ years & 2 \\
& $51-60$ years & 3 \\
& $61-70$ years & 1 \\
& Unknown & 1 \\
Cultural group & Mixed race English & 2 \\
& Black isiXhosa & 3 \\
& Black Setswana & 11 \\
& White Afrikaans & 7 \\
Nursing registration category & Registered nurses and midwives & 6 \\
& Enrolled nurses & 1 \\
& Care workers & 3 \\
\hline
\end{tabular}

Semi-structured interviews were conducted. Thus, a predetermined set of open-ended questions were asked and probing questions were posed for clarification (Fylan, 2005). The interviews were conducted in either English or Afrikaans, depending on the participant's language preference. The interviews were scheduled for $30 \mathrm{~min}$, at a time that was determined at the convenience of the participants. The following questions were included in the interview schedule in order to reach the objectives of the study:

- To which cultural group would you say you belong to?

- Do you think that different cultural groups have an influence on the workplace and the way in which people do their work?

- What do you think are the unique contributions of your own cultural group to the hospital?

- What do you believe are the unique contributions that other cultural groups in the hospital (e.g. white Afrikaans, white English, mixed race Afrikaans, mixed race English, black Setswana, isiZulu, Sesotho, isiXhosa nurses) make to this hospital?

- Would you like to know what the unique contributions of the cultural groups in this hospital are? How would you like to be informed about it?

- Do you think if you have an awareness of these different contributions of the different cultural groups in the hospital, you would develop an appreciation for them?

\section{Data recording}

Permission was obtained from the participants to record the interviews on an electronic device in order to capture their exact responses to the interview questions. Each interview was transcribed and captured in an Excel sheet. Prior to the data analysis, the interviews were carefully compared to the voice recordings to confirm that the researcher had transcribed it accurately. All the voice recordings of the interviews together with the transcribed interviews were saved on a password-protected computer so that the confidentiality of the data stayed protected at all times.

\section{Strategies employed to ensure data quality and integrity}

Four important strategies for ensuring quality research are offered by various researchers in the qualitative field. 
These criteria presented by Lincoln and Guba (1999) in conjunction with the work of De Vos, Strydom, Fouché and Delport (2011) were utilised in this study.

To ensure the credibility (i.e. the degree to which a subject has been identified and described accurately; Lincoln \& Guba, 1999) and conformability (the notion of objectivity in qualitative research; De Vos et al., 2011) of the research, the researchers remained objective at all times during the research process. Co-coders were used to ensure that the findings portrayed a true reflection of the participants' experiences (De Vos et al., 2011). Transferability (the degree to which results can be applied and transferred to other contexts; Lincoln \& Guba, 1999) and dependability (the accuracy and consistency of the qualitative research; De Vos et al., 2011) were ensured by accurate and meticulous reporting of the procedures followed in this study and reporting on the context within which the research occurred. The salient features were also described in depth to ensure transferability.

\section{Data analysis}

After the interviews had been transcribed onto an Excel spreadsheet, the data were analysed. The process of content analysis as described by Elo and Kyngas (2008) was followed to analyse the data.

\section{Phase 1: Preparation:}

- Select unit of analysis. In the case of this research, the unit was each of the responses provided to each of the interview questions. The response was considered as a whole and was then broken down to analyse each sentence or central idea.

- Making sense of the whole. The researcher became immersed in the data, read and reread through the responses of participants several times to become completely familiar with the content.

\section{Phase 2: Organising:}

- Open coding: The researcher read the text and made preliminary notes, whilst categories were freely generated.

- Grouping categories (codes): Categories that are similar or dissimilar in content were grouped together to reduce the number of categories, creating broader, higher order categories.

- Abstracting: Categories and sub-categories were named and described to accurately reflect the content of the category.

\section{Phase 3: Reporting:}

- The study results were reported by providing clear descriptions of the categories identified through the content analysis process, substantiating the accounts with direct quotations. Specifically, the researchers aimed to provide the reader with clear descriptions of the participants' responses.
It was essential that, prior to the interviews, the researchers had a clear understanding of their own cultural beliefs and how they might affect the participants, should the researchers have not behaved in an ethical and objective manner. In this research project, the researchers placed a strong emphasis on behaving as neutral and objective as possible so that they could not influence the participants with their own beliefs and values (Creswell, 2009).

\section{Ethical consideration}

Ethics clearance has been granted by the Economic and Management Sciences Research Ethics Committee (EMSREC) of the North-West University on 22 June 2016 (EMSMHW16/05/19-01/02).

\section{Results}

In the following section, important findings of this study will be thoroughly presented and put into contextual perspective.

\section{Identification of cultural groups}

The participants were asked to describe the cultural group they believe they belong to. This question was asked to give the researchers more insight into what descriptors participants use to describe their cultural group. From the answers, it became evident that language was used as the most common descriptor for a cultural group. Many of the participants also understand culture as a combination of both their language and ethnicity.

\section{The influence of different cultural groups in a nursing environment}

All the participants were asked whether they believe that one's cultural background has an influence on the workplace and the way in which people do their work. The majority of the participants confirmed that they do believe that a person's culture may influence the way in which they perform their work. Below are some of the responses of these participants:
'We have different beliefs.' (P1; white Afrikaans-speaking participant)
'We're all different and everyone's outlook is different.' (P1; white Afrikaans-speaking participant)
'If someone is very cultural it shows in their personality...the way in which we perceive things are not the same.' (P12; mixed race English-speaking participant)
'There are a few things in which different cultural groups do things differently ... when it comes to the workplace, there are many things that had to give and then you treat the patient the way in which you were trained.' (P13; black Setswana-speaking participant)

The three participants, who indicated that they do not believe that culture has an influence on the way work is done, pointed out that in this specific working environment, the training nurses receive is standard and the work has to be done according to the hospital and their prescribed standards and procedures. Therefore, the way in which 
the work is performed must be done in the same specific way by everyone regardless of their culture:

'If everyone receives the same training...the work has to be done the same way by everyone.' (P6; white Afrikaans-speaking participant)

\section{The unique contributions of cultural groups}

The results in this category were obtained by asking the participants a question regarding the unique contributions of their own cultural group in the workplace, and how these contributions add value to their workplace and role as a nurse. It should also be noted that some of the participants focused on the differences in how nurses from different (other) cultural groups do their work, rather than on the specific contributions from their cultures to the work. An explanation of the responses by the different cultural groups is provided next.

Black Setswana speakers $(n=3)$ : One participant indicated that they believe that their cultural group shows the ability to accept responsibility (P14; black Setswana-speaking participant). The two other participants indicated that there is no contribution from their own culture to the workplace. Reasons provided were that it is more one's personality that has an impact on the way work is done and that they are not fixed in the old cultural ways anymore and that they have modernised:

'I don't think that is really applicable anymore, because we are not in that old ways anymore, the way our parents raised us changed over generations and we are more modernised now. I don't know much about the ethics of my culture.' (P15; black Setswana-speaking participant)

Black isiXhosa speakers $(n=2)$ : Both participants indicated that their cultural group does indeed offer unique strengths to the workplace. One of the black isiXhosa-speaking participants indicated that her cultural group has good leadership skills and the ability to solve conflict right away in a calm manner. This participant also mentioned how they were raised to be independent and assertive which are also things that spill over in their working environment:

'You must be strong, you must know how to stand up for yourself, you must know how to present yourself; so that is something we have been taught since we were young.' (P16; black isiXhosa-speaking participant)

The other participant mentioned that respect for others and respect for older people is something they have a high regard for in their culture and which they contribute to the workplace. The participant also explained how they can sometimes be misunderstood by white colleagues:

'When we keep quiet, the white sister for example will think that I'm stubborn, but according to my culture I must stand back, and maybe only in a few hours or days I can go and talk to her and explain. Because talking back in my culture is disrespectful.' (P17; black isiXhosa-speaking participant)
White Afrikaans speakers $(n=11)$ : Five of the participants in this group pointed out that as compared to other cultural groups, the white Afrikaans culture has a caring nature when it comes to patient care:

'Us white people have more of a caring nature.' (P2; white Afrikaans-speaking participant)

'We tend to sympathise better.' (P11; white Afrikaans-speaking participant)

'We care for our fellow man.' (P5; white Afrikaans-speaking participant)

Six of the white Afrikaans-speaking participants emphasised the importance of their cultural influence on patient care, going above and beyond to ensure that the patient is comfortable and satisfied and will tend to every small detail with care. It was mentioned that this type of detailed care may be overlooked by nurses of other cultural groups. It was further emphasised that the white Afrikaans culture cares equally for patients of all cultures. It was also mentioned that they respect the privacy of the patients:

'I think that is something of our cultural group, caring for each other, equally for everyone.' (P5; white Afrikaans-speaking participant)

'With patient care, we tend to the smallest details; like checking if the patients are comfortable and satisfied, all of those small things we tend to, which other groups maybe overlook.' (P5; white Afrikaans-speaking participant)

'We tend to give the patient more privacy and we respect his or her privacy.' (P6; white Afrikaans-speaking participant)

The interviews also revealed that the white Afrikaansspeaking nurses consider themselves to be responsible and conscientious when it comes to their work and that their work must be done in a precise manner. It was mentioned that the white Afrikaans culture may have a greater sense of responsibility when compared to other cultural groups:

'We are more responsible.' (P2; white Afrikaans-speaking participant)

'Have to do things right from the start, without mistakes.' (P4; white Afrikaans-speaking participant)

'We will go to work even if we are sick - others will call in and say that they can't go to work. We don't easily do that; we accept that we have responsibilities.' (P2; white Afrikaans-speaking participant)

It was also suggested that the white Afrikaans-speaking nurses are willing to invest additional effort in their work, and will do more than what is expected of them. They are also willing to stay at work longer than others when it is required:

'The extra effort we put into our work...that extra mile we will go, we will do our work and then a bit extra, because it is the way we were raised, it is also out of politeness.' (P7; white Afrikaansspeaking participant) 
'The sacrifices we make, like I would, for example stay longer at work in order to finish my work.' (P9; white Afrikaans-speaking participant)

Lastly, three of the participants in the white Afrikaansspeaking group mentioned that this group in general is more considerate by speaking in a language that everyone from another cultural group can understand:

'We are calmer and are more considerate by speaking in a language that everyone understands.' (P11; white Afrikaansspeaking participant)

'We are more careful with what we say, we will make sure that the other person understands what you are saying, we will explain over and over.' (P10; white Afrikaans-speaking participant)

It was also mentioned by three white Afrikaans-speaking participants that this cultural group handles conflict well:

'We handle conflict with grace and don't jump around and make a scene.' (P11; white Afrikaans-speaking participant)

'Talk to the person and try to find a solution or middle ground.' (P6; white Afrikaans-speaking participant)

\section{Perceptions of the unique contributions of other cultural groups}

The results of this category were obtained by asking the participants to elaborate on the contributions they believe their colleagues from different cultures bring about in the workplace. Although participants were asked to comment specifically on the contributions, they had a tendency to focus more on the differences between different cultural groups, rather than on the contributions. An interesting observation in this study was that when nurses were asked about the contributions of other cultural groups, most of the white Afrikaans-speaking participants referred to the black Setswana and black isiXhosa-speaking nurses as their 'black' colleagues, without distinguishing the differences between the separate cultural groups. Thus, they consider them as one group based on their race, rather than recognising the differences between different cultural groups that exist amongst black colleagues. A discussion of the responses of the different cultural groups follows next.

Black Setswana speakers: It was mentioned that the black Setswana-speaking group will not necessarily start a close friendship in which they open up and talk freely about their emotions with someone from another cultural group:

'They like to keep everything to themselves, in other words, they won't talk openly about problems or emotions etc. ... very easy to guide.' (P12; mixed race English-speaking participant)

It was also mentioned that the Setswana group is:

'Very easy to teach and will follow orders.' (P12; mixed race English-speaking participant)

Black isiXhosa speakers: The black isiXhosa-speaking group was also described as being a supportive culture that looks out for one another. However, they will not start a friendship with you if you are not from their own culture:

'They will always support each other and look out for each other, but if you are not their cultures they will not really start a friendship with you no.' (P12; mixed race English-speaking participant)

Black other: The white Afrikaans-speaking participants found it difficult to distinguish between the different cultural groups, such as the black isiXhosa and black Setswanaspeaking groups, and therefore just referred to these colleagues as 'black nurses'. A central theme that emerged from the interviews is the valued role of black colleagues as translators, to help the white Afrikaans-speaking nurses to explain something to a patient from a different language. This helps the patient to understand and feel comfortable. It was also mentioned that this ability of black nurses to speak and understand different languages enables them to take the lead in certain situations:

'They contribute a great deal in the form of a translator, and not necessarily a nurse only, you can call any worker and they are always willing to help.' (P10; white Afrikaans-speaking participant)

'That is something that really stands out, the different languages they are able to speak.' (P7; white Afrikaans-speaking participant)

'We admit a lot of people ... from all groups, so many times ... I don't understand them, or they don't understand me, then they help me a lot $\ldots$ they actually take the lead then.' (P11; white Afrikaans-speaking participant)

Patient care of black nurses was another topic that was highlighted by six of the white Afrikaans-speaking participants. It was explained that because people from black cultural groups tend to take sick family members into their homes, and elderly family members are taken into their homes and taken care of, they have this acquired ability to take care and sympathise with people:

'Black cultural groups are very good with patient care because they are used to taking care of their parents and grandparents, so in that regard they are very good.' (P9; white Afrikaans-speaking participant)

A particularly interesting finding was that the black cultural group was described as sensitive, careful and caring towards patients that are not from their own cultural groups, especially white patients. One of the participants (P3; white Afrikaans-speaking participant) is of the opinion that this may be because it is the black cultural groups' way of adapting to the white Afrikaans culture and also because older white individuals are viewed as being weaker and more vulnerable and not as strong as older black individuals:

'But I can also say that they do not have a great deal of empathy for their own culture (black culture) lying in bed, they show more empathy for other cultures, especially white people.' (P6; white Afrikaans-speaking participant) 
'I think it's their way of adapting to our culture because they think the white old people are much weaker and resilient and they should be nurtured.' (P3, white Afrikaans-speaking participant)

The black Setswana-speaking group was described as a group that tends to speak louder in order for other individuals to hear that they are not being gossiped about:

'Speak loud so that others can hear that they are not being gossiped about.' (P2; white Afrikaans-speaking participant)

White Afrikaans speakers: With this cultural group there seems to be a central topic of respect that exists. One black isiXhosa-speaking participant and one black Setswanaspeaking participant mentioned that their white Afrikaansspeaking colleagues value respect from others:

\footnotetext{
"The whites don't really like if we call them "ouma" and "oupa." We are supposed to say Mr. and Mrs.' (P17; black isiXhosaspeaking participant)

'What I have learned [from the white Afrikaans culture] is that it is disrespectful to say to each other "you" especially if it is an older person.' (P13; black Setswana-speaking participant)
}

One participant stated that the white Afrikaans-speaking nurses like to teach others:

'If they know something, they will teach you. I have learnt a lot from Afrikaans white people.' (P12; mixed race English-speaking participant)

Mixed race English: Not many remarks were made about the mixed race English-speaking group, as there are not many nurses in this hospital that come from this cultural group. This group was described as sympathetic towards their patients:

'Because they take care of their parents and children, they tend to show a lot of sympathy.' (P9; white Afrikaans-speaking participant)

It was also mentioned that the mixed race English-speaking group, as well as the mixed race Afrikaans-speaking group, will speak in the language the patient feels comfortable with, whether it be English or Afrikaans.

\section{The need for cultural awareness}

Next, the participants were asked if they would like to know more about the unique contributions the different cultural groups in the hospital have to offer. All 17 of the participants indicated that they would indeed like to know more about the different cultures and how they contribute positively to the workplace. Below are some of the direct responses from the participants:

'Yes I would like to know ... Maybe we can mix some things of our cultures so that we understand each other better.' (P17; black isiXhosa-speaking participant)

'Because maybe these contributions might be there but I don't notice them or know of them.' (P16; black isiXhosa-speaking participant)
'There are so many things that we don't know about. I think if one knows about these things, one would have much more respect for it. I think in a workplace where there are so many different cultures it is important to become aware of these things.' (P2; white Afrikaans-speaking participant)

In addition to the above, the interviewer also asked the participants how they would like to be made aware of other cultures' contributions to the workplace. Ten of the participants specified that they would like to be informed in an informal, social setting where they could tell each other about their cultural customs and values and how they bring this to the workplace and ask questions openly:

'Us black people, we don't like to get information on paper, because you can't ask a paper questions, so if we can have a gathering or a meeting, so that we can also comment and say how we feel and problems we experienced.' (P17; black isiXhosaspeaking participant)

Four participants from the white Afrikaans-speaking group stated that a cultural workshop or diversity course with an expert in the field would be the best way for them to get an understanding of different cultural groups:

'I think like a type of a conference, or a talk by someone who is learned in the field.' (P4; white Afrikaans-speaking participant)

Other participants said that they would like to be informed by means of a written letter, pamphlet, email or news bulletins. The participants explained that it is easier to recall information if it is done in such way, and that they could read the information in their own time. One participant explained that something like an Employee Assistance Programme (EAP) programme in terms of cultural awareness would be very nice and helpful in order to gain understanding and help with the already built up tension between the colleagues from different cultures.

\section{The appreciation of diversity}

During the interviews, the participants were also asked whether they believe that an awareness of the unique contributions of every cultural group that they work with may result in an appreciation for these unique contributions. Given that all 17 participants indicated that they would indeed develop an appreciation for these unique contributions from other cultural groups if awareness is raised, it clearly shows that there is a need for this development specifically in this hospital environment. The majority mentioned that it would help them to understand each other and work together better and in cohesion with each other:

'It would really help us to work better together and understand each other, and if we have that understanding, we would be in a better place. I think we should combine everybody's unique contributions. We will definitely work better together, and even with us, I mean we are blacks yes, but we are from different cultures, and it would also be nice if people can understand that and learn about our cultures.' (P16; black isiXhosa-speaking participant)

'And with my colleagues, we will understand each other better and work together better. Culture in the workplace counts a lot, 
it doesn't mean we have to practice it here, but only one thing that covers it all and that is respect. We have to work together, accept each other and feel comfortable and free to do anything and everything.' (P17; black isiXhosa-speaking participant)

'We will work better together with our colleagues. I feel that our black colleagues always do everything to fit in with our culture and we don't do enough to fit in to theirs or to get to know them and do something the way they want it to be done. They must constantly do things the way we want it to be, and we get angry if they do it different, but we don't take into account that it might be their culture's way of doing things.' (P1; white Afrikaans-speaking participant)

One participant mentioned that if one learns about other cultures and gains an understanding on why they do things in a certain way, he or she will learn to accept, adapt and accommodate one another. By doing this, one will not go against the culture of someone else or offend in any way; instead, one will think of new ways to do things, to accommodate colleagues from different cultural backgrounds. One participant said that:

'Culture is sometimes a big confusion and it leads to dissension between people, if we get to know more about each other's cultures we will learn to accept each other.' (P11; white Afrikaans-speaking participant)

Another participant also stated that by learning to accept and appreciate the differences is to our own, the person from the other culture and the organisation's benefit. It was also mentioned that:

'You don't change one's culture, you accept and respect it and you cooperate.' (P3; white Afrikaans-speaking participant)

Finally, an interesting reflection was made by some participants that there are so many things they do not know about other cultures and that they can learn from each other. It was also mentioned that in order to provide efficient patient care, it is important for different cultures to work together:

'Everybody is unique and there are so many things we can learn from each other.' (P16; black isiXhosa-speaking participant)

'One has to be open and receptive to new information and building new knowledge. The more you have of that, the better we can work together with each other and our different cultures. At the end of the day the patient is the most important and if we don't have an effective team, the patient would suffer and we won't be able to do our work the way we are supposed to.' (P4; white Afrikaans-speaking participant)

\section{Discussion}

\section{Outline of the results}

The primary objective of this research study was to explore the unique contributions of different cultural groups within the nursing environment in South Africa. For the purpose of this study, it was important to first determine the cultural groups to which the participants belong. This has been proven to be problematic within the South African context
(Straub, Loch, Evaristo, Karahanna, \& Srite, 2002) because each individual is influenced by a plethora of different cultural and sub-cultural aspects. As Thomas and Bendixen (2000) explained, it is unfitting to talk about South African cultures as a homogenous culture on its own, but rather a set of different cultures and ethnic groups that may have differing or similar values, despite their very different backgrounds. Amongst research there is a common assumption that any individual living in a particular place belongs to a single culture; for example, someone who lives in South Africa is automatically classified as being a member of an all-encompassing African culture (Straub et al., 2002). Thomas and Bendixen (2000) went further by saying that one has to take into account a person's race, language and religion to gain an understanding of the values that people from different ethnic or cultural backgrounds bring into their workplaces. To address the issue of defining cultural groups, the researcher asked the participants themselves to identify their cultural group, by simply asking them to name the cultural group they belong to. The majority of the participants used a combination of their language and ethnic groups as a common descriptor of culture (for example black Setswana, white Afrikaans). It is common for South Africans to describe the cultural group they belong to by using their language together with ethnicity (see Cilliers, 2007; Triandis, 1972; Van der Merwe, 2009), which serves as an indication of the unique values, beliefs and customs a group may share.

The first objective of the study was to explore the unique contributions individuals believe their own cultural group can bring to the organisation. Firstly, it was explored whether nurses believe that cultural background may have an influence on the workplace and the way in which people do their work. From the results, it was found that the majority of the participants recognised that culture does indeed influence the way in which work is done. Participants mentioned that as culturally different individuals working together they all have their own outlooks on life as well as differing values, beliefs and interpretations, which may influence the way in which they do their work. According to Grossberg, Struwig and Pallay (2006), members of a group tend to think alike because they feel like this binds them as a group and also from their upbringing in that specific group. The way in which work is done can, therefore, differ because of the notion that members of a cultural group share a common understanding and interpretation of certain aspects (such as caretaking) and in this manner also perceive themselves as different from other groups (Iguisi, 2009).

Few of the participants did, however, indicate that they do not believe that culture has an influence on the way work is done. These nurses argued that the way in which the work is done has to be according to the hospital's prescribed standards and procedures, and there is therefore little room for personal values and beliefs to influence their work. Some participants also indicated that the nursing education and training they received have a stronger influence on the way nurses do their work than their personal background and 
culture. Research confirms that training is fundamental to the development of human resources (Salas \& Cannon-Bowers, 2001); however, only a small number of organisations display a positive relationship between training and positive change. It can therefore be argued that even though training has a strong influence on the way a person does his or her work, being trained in a culturally competent way, by a culturally competent trainer, will increase the effectiveness of training in the culturally diverse world we live in (Cilliers, 2011).

Participants also touched on the aspect of personality and how that may influence the way in which they do their work, rather than the cultural group that they belong to. This speaks to an individual's own personal values, beliefs and preferences regarding the way the work is done. One of the longstanding arguments is that personality characteristics influence work values, therefore individuals will search for jobs suited to their personality characteristics (Furnham, Petrides, Tsaousis, Pappas, \& Garrod, 2005). It is also true that culture also affects one's personality together with one's behaviour, perceptions and work values (Iguisi, 2009). Therefore, personality may influence the way one works, however culture may also influence personality, which in turn has an influence on the way work is performed.

Next, the participants were asked what they believe are the unique contributions that stem from their own cultural group, that they offer to the workplace. Black Setswana-speaking participants indicated that accepting responsibilities is something that they believe is a unique contribution from their own cultural group that is beneficial to the workplace. Iguisi (2009) explained that this acceptance of responsibilities in the workplace could be because, in this culture, members of the group are given responsibilities in the community from early childhood until death. Emphasis is also placed on age groups and how different age groups socialise members in taking over responsibilities in the society. It was also mentioned that some of the younger generations are not fixed in the old cultural ways anymore and that they have modernised, which is also indicated by some literature on these specific cultural groups. According to the work of Allegritti and Gray (2005), on some cultural insights within the South African context, there is a new generation of young people who have grown up in urban townships without strong connections to African cultural ways and adapt to the environment in which they work.

Black isiXhosa-speaking participants reported that good leadership skills and the ability to solve conflict right away in a calm manner are a contribution that they offer the organisation that stems from their cultural values. It was also mentioned that isiXhosa people are raised to be independent and assertive, which are also things that spill over in their working environment. Children in the isiXhosa communities were raised to be strong and assertive and because of families that were split as both mother and father had to work for an income, the eldest child would often take care of the family duties and responsibilities (Barr, 2008). Also, respect for others and respect for older people are something they have a high regard for in their culture and this is their contribution to the workplace. This is something that characterises most African cultures, and age specifically plays an important role in African cultures (Iguisi, 2009).

White Afrikaans-speaking participants in this study described themselves as more caring in nature, specifically when it comes to patient care when compared to other cultural groups. Going above and beyond to ensure that the patient is comfortable and tending to every small detail with care, are some of the ways in which this group described themselves. This is in line with the literature that suggests that, traditionally, in the white Afrikaner culture, Afrikaans females are considered as caregivers and mothers in nature (Frizelle \& Kell, 2010). The interviews also revealed that the white Afrikaans-speaking nurses consider themselves to be responsible and conscientious when it comes to their work and that their work must be done in a precise manner. If one takes a look back into the history of the white Afrikaner, children in white Afrikaans-speaking families are raised to be respectful of their elders, to be good corporate citizens, to be self-preserved, and to do something well from the start, because of the rigid ways in which their parents were raised (Van der Merwe, 2009). Participants also indicated that the white Afrikaans-speaking cultural group in general is more considerate by speaking in a language that everyone in the group understands. Van der Merwe (2009) mentioned in his work that the 'Afrikaner' (referring to the white Afrikaansspeaking group) found themselves in a radically changing world in the post-apartheid era and many of their cultural values, beliefs and traditions fell away and since then their outlook on life and the world has often been based on the norms of Western civilisation, possibly explaining the consideration for other cultures.

The second objective of this study was to investigate what according to one cultural group, another cultural group can contribute to the organisation. With regards to this objective, the researchers also raised the question to the participants to elaborate on the contributions they believe their colleagues from other cultures bring about in the workplace. What was particularly interesting was that, when posed these questions, the participants focused more on the differences in how nurses from different (other) cultural groups do their work, rather than the specific positive contributions from these cultures to the workplace. It is not uncommon for people to focus on differences between groups. For example, it is suggested that people from the same cultural group share a common understanding and have certain views pertaining to certain aspects of work, which make them perceive themselves as different from other groups (Iguisi, 2009). The social identity theory could also be one of the main reasons why people do not recognise the positive contributions that people from other groups can offer to the organisation (Abrams \& Hogg, 1988), simply because they do not acknowledge that another group could contribute positively to the environment. 
When participants were asked to elaborate on the unique contributions that the other cultural groups in the hospital can offer to the work environment, the white Afrikaansspeaking participants were unable to distinguish between the black isiXhosa and black Setswana-speaking group. Mostly, the white Afrikaans-speaking participants referred to the 'black' colleagues in general. With the white Afrikaansspeaking participants talking about their 'black' colleagues, referring to their ethnicity rather than the different cultural groups, it may be implied that cultures in South Africa are being discredited and their importance undermined. It is therefore important to attend to this matter in the workplace, for employees to become aware of the richness and the numerous benefits that cultural diversity encompass in the workplace. Following is a discussion of the unique contribution of each cultural group.

Both the black Setswana-speaking nurses and the black isiXhosa-speaking group were described as speaking loud, even though they work in a hospital environment that requires peace and quiet. According to FASSET (2013), it is quite common for all African cultures to speak loudly. It is explained that according to their value system they are not allowed to whisper as it is perceived as being rude or gossiping about another individual. This group is also quite comfortable to laugh or cry loudly in public. When describing the unique contributions of the white Afrikaans group, a central theme of the value of respect from others emerged. Patterson (2004) confirmed this by stating that the 'Afrikaner' has a predisposition for order and respect; however, it is showing a tendency to disappear.

From the above, it is evident that the participants showed little insight into the unique positive contributions that people from different cultural groups can bring to the workplace. The social identity theory might explain this. This theory suggests that if one belongs to a group, this group is seen as the in-group and one is focused primarily on the positive evaluation of one's in-group and differentiates themselves from the other, or out-groups. The focus is therefore on their own group and the superiority of their group, rather than on other groups and what they can bring to the table (Tajfel \& Turner, 2004). This mentality amongst colleagues could be one of the main reasons why people do not recognise the positive contributions that people from other groups can offer in the organisation. This lack of knowledge about different cultures is concerning, because an appreciation for diversity and the effective management of diversity in the workplace may be dependent on the awareness of and a focus on the strengths of all employees (Jayne \& Dipboye, 2004).

The third objective of this study was to investigate whether an awareness of the unique contributions from individuals from different cultural groups could contribute to an appreciation of diversity in the workplace. All of the participants indicated that they would like to know more about the unique contributions the different cultural groups in the hospital have to offer. The researchers were also interested in the participants' suggestions on how they would like to receive information about the unique contributions of different cultures in their hospital. Suggestions were made by participants to share information about cultural customs, values and contributions in informal, social settings (where open discussions can be held), formal workshops, as well as written communication such as letters, pamphlets, emails or news bulletins. Collins and Pieterse (2007) in their research done on effective approaches to develop cultural awareness, considered all different modes of training and the limitations thereof. They have found that adults learn best when they are confronted with real-life situations where they are considered as the stakeholders. The proposed method of training in cultural awareness is the use of a critical incident analysis. The critical incident analysis is a reflective learning type that involves reflection, personal experience and the transformation of significance and knowledge (Collins \& Pieterse, 2007). This approach to raise cultural awareness examines situations and encounters that take place in a real-life setting - in other words, the day-to-day work encounters that the participants face.

The participants also mentioned that if one learns about other cultures and gains an understanding of why they do things in a certain way, he or she will learn to accept, adapt and accommodate one another. They also indicated that if they are made aware of the unique contributions that the different cultural groups bring to the workplace, they will work better together as they will have a deeper understanding of each other and their different cultural groups. These statements are supported by the work of Shen, Chanda, D'netto and Monga (2009) that a diverse workforce that is managed effectively and that has learnt to value the uniqueness of different cultural groups, displays better cooperative behaviour and has the capability of raising the organisation's effectiveness, efficiency and profitability. Managing diversity in a way that focuses on the appreciation of the cultural contributions of the various cultural groups enables the full utilisation of the skills and potential of all the employees in the workplace (Shen et al., 2009).

\section{Practical implications}

Based on the results, the practical implication of this study is the identification of unique cultural contributions that people from different cultural groups can bring to the workplace. The lack of well-defined cultural diversity incentives has proven to be a great barrier in the effective management of diversity in the workplace. It is evident that there is confusion with regard to culture, what it comprises, how it can bring opportunities and a better understanding if an awareness of the unique contributions is made, which will, in turn, foster a greater appreciation for diversity. Participants reported on the differences between the groups, and how the way in which the work is done differs from one cultural group to another; however, they did not recognise the positive contributions. The way in which diversity has been managed up until this day has not indicated that it has been done for 
the right moral or social reasons. Unfortunately, the focus of the South African legislature is also to comply with the minimum requirements and not necessarily the appreciation of diversity in the workplace, hence the major gap currently in South Africa.

\section{Limitations and recommendations}

The study was limited to nurses from two hospitals in the North West Province. The sample size was relatively small and not all cultural groups were equally represented in the study. The use of a volunteer sampling strategy resulted in the underrepresentation of some groups, which poses a threat to the validity of the study results. It is therefore suggested that future research should include more participants from an array of cultural groups by means of a stratified sampling strategy to ensure equal representation of different groups.

Furthermore, some participants seemed hesitant or somewhat uneasy when posed questions that may come across as sensitive. This may be because the interviewer was from a different cultural group than some of the participants, and therefore participants may have felt that they could not voice their opinion or observations of that cultural group in full honesty. It is recommended that in future research interviews should be conducted by people from different cultural groups to best assist with the preferences of participants and to get the most open and honest responses possible.

Another possible limitation of the study was that it focused primarily on nurses. The researchers thought it to be wise to use nurses to participate in the study as they have to work in close collaboration with each other, for long hours and they are from widespread cultural backgrounds. It is recommended that future research should expand the context within which the study is done, and focus on a more extensive variety of participants from different samples.

\section{Conclusion}

To conclude, the results of this study demonstrate that, in the workplace, employees are not aware of the contributions that people from other cultural groups bring to the workplace. If employees are unaware of the unique attitudes, beliefs and values of their colleagues from a culture different to their own, it may negatively influence their perceptions, interactions and views of that person within the work context. The results, however, also indicated that there certainly is a need and craving of employees to understand what it is that other cultural groups bring to the workplace that is unique to their culture and that would impact the workplace positively. Participants also indicated that they believe it would help them work better together as they would have developed a greater understanding and sensitivity for one's culture and how it influences the way in which they do their work.

As a result of this study, awareness was raised amongst organisations to invest in the cultural diversity of their people to foster an organisational culture where diversity is appreciated. As Whitmore (2002) stated, 'I am able to control only that of which I am aware. That of which I am unaware controls me. Awareness empowers me' (p. 33). Organisations should therefore empower their employees to develop a skill set in which they are sensitive enough to notice cultural differences, and then also be willing to adjust their behaviour as a sign of respect and appreciation for the people of other cultures (Bhawuk \& Brislin, in Hammer, Bennett, \& Wiseman, 2003).

\section{Acknowledgements}

\section{Competing interests}

The authors have declared that no competing interests exist.

\section{Authors' contributions}

VK was a master's student, where CE acted as supervisor and LR as co-supervisor. All three authors were involved in the conceptualisation and design of the project. VK collected the data, and all three authors analysed the data and contributed to the writing of the manuscript.

\section{Funding information}

This research received no specific grant from any funding agency in the public, commercial or not-for-profit sectors.

\section{Data availability statement}

Data are available on request.

\section{Disclaimer}

The views and opinions expressed in this article are those of the authors and do not necessarily reflect the official policy or position of any affiliated agency of the authors.

\section{References}

Abrams, D., \& Hogg, M.A. (1988). Comments on the motivational status of self-esteem in social identity and intergroup discrimination. European Journal of Socia Psychology, 18(4), 317-334. https://doi.org/10.1002/ejsp.2420180403

Allegritti, I., \& Gray, M. (2005). Mamphele Ramphele and isiXhosa culture: Some insights on culture, self-determination and human rights for South African social work. Social Work/Maatskaplike Werk, 41(2), 131-142.

Barr, B.K. (2008). The culture of AIDS in isiXhosa society. University of Tennessee honors thesis projects. Retrieved from http://trace.tennessee.edu/utk_chanhonoproj/1149

Cilliers, F. (2007). A systems psychodynamic exploration of diversity management: The experiences of the client and the consultant. South African Journal of Labour Relations, 31(2), 32-50.

Cilliers, F. (2011). Positive psychology leadership coaching experiences in a financia organisation. SA Journal of Industrial Psychology, 37(1), 14. https://doi. org/10.4102/sajip.v37i1.933

Cilliers, F., \& Stone, K. (2005). Employment equity practices in three South African information technology organisations: A systems psychodynamic perspective. South African Journal of Industrial Psychology, 31(2), 49-57. https://doi. South African Journal of
org/10.4102/sajip.v31i2.193

Coetzee, O. (2007). Exploring interpersonal and inter-group diversity dynamics in South African organisations by means of a theoretical model. Unpublished D Com thesis. Pretoria: University of South Africa.

Coetzee, M. (2015). Identity theory and research in the South African organisationa context. SA Journal of Industrial Psychology, 41(1), Art. \#1282, 2 pages. https:// doi.org/10.4102/sajip.v41i1.1282 
Coetzee, M. (2016). Measuring and optimising employee engagement in Africanised multi-culturally diverse contexts Employee engagement in a South African context, Hester Nienaber \& Nico Martins (Eds.): Book review. SA Journal of Industrial Psychology, 42(1), 1-2. https://doi.org/10.4102/sajip.v42i1.1404

Coetzee, O., \& Cilliers, F. (2012). Humour as defence against the anxiety manifesting in diversity experiences. SA Journal of Industrial Psychology, 38(2), 9. https://doi. org/10.4102/sajip.v38i2.990

Collins, N.M., \& Pieterse, A.L. (2007). Critical incident analysis based training: An approach for developing active racial/cultural awareness. Journal of Counseling and Development, 85(1), 14. https://doi.org/10.1002/j.1556-6678.2007.tb004 39. $x$

Cooperrider, D.L., \& Sekerka, L.E. (2006). Toward a theory of positive organizational change. In J.V. Gallos (Ed.), Organization development: A Jossey-Bass reader (pp. 223-238). San Francisco, CA: John Wiley \& Sons.

Cox, T.H., Jr. (1994). Cultural diversity in organizations: Theory, research and practice (1st edn.). San Francisco, CA: Berrett-Koehler Publishers.

Creswell, J. W. (2009). Editorial: Mapping the fields of mixed methods research. Journal of Mixed Methods Research, 3(2), 95-108. https://doi.org/10.1177/1558689808330883

Davidson, M.N., \& James, E.J. (2006). The engines of positive relationships across difference: Conflict and learning. In J.E. Dutton \& B.R. Ragins (Eds.), Exploring positive relationships at work: Building a theoretical and research foundation (pp. 137-158). Mahwah, NJ: Lawrence Erlbaum.

De Beer, J. (2016). Jealously guarding a sense of "us." Newsletter 7. Retrieved from http://eepurl.com/bZdqxH

De Vos, A.S., Strydom, H., Fouché, C.B., \& Delport, C.S.L. (2011). Research at grass roots: For the social sciences and human service professions (4th edn.). Pretoria: Van Schaik.

Elo, S., \& Kyngäs, H. (2008). The qualitative content analysis process. Journal of Advanced Nursing, 62(1), 107-115. https://doi.org/10.1111/j.1365-2648.2007.04569.x

Finance and Accounting Services Sector Education and Training Authority (FASSET). (2013). Culture and diversity in the workplace handbook. Johannesburg: FASSET.

Frizelle, K., \& Kell, G. (2010). A contextual account of motherhood. Psychology in Society, 39(1), 26-44.

Furnham, A., Petrides, K.V., Tsaousis, I., Pappas, K., \& Garrod, D. (2005). A crosscultural investigation into the relationships between personality traits and work values. The Journal of Psychology, 139(1), 5-32. https://doi.org/10.3200/ JRLP.139.1.5-32

Fylan, F. (2005). Semi structured interviewing. A handbook of research methods for clinical and health psychology. In J. Miles \& P. Gilbert (Eds.). A handbook of research methods for clinical and healthy psychology (pp. 65-78). New York, NY: Oxford University Press.

Gardner, D. (2005). Ten lessons in collaboration. Online Journal of Issues in Nursing 10(1). https://doi.org/10.3912/OJIN.Vol10No01Man01

Grossberg, A., Struwig, J., \& Pillay, U. (2006). Multicultural national identity and pride. In U. Pillay, B. Roberts \& S. Rule (Eds.), South African social attitudes: Changing times, diverse voices (pp. 54-76). Cape Town: HSRC Press.

Hammer, M.R., Bennett, M.J., \& Wiseman, R. (2003). Measuring intercultural sensitivity: The intercultural development inventory. International Journal of Intercultural Relations, 27(4), 421-443. https://doi.org/10.1016/S0147-1767(03) 00032-4

Human, L. (2005). Diversity management for business success. Pretoria: Van Schaik.

Iguisi, O. (2009). Cultural dynamics of African management practices. Unpublished $\mathrm{PhD}$ thesis. University of Stirling, Stirling.

Jackson, S.E., Joshi, A., \& Erhardt, N.L. (2003). Recent research on team and organizational diversity: SWOT analysis and implications. Journal of Management 29(6), 801-830. https://doi.org/10.1016/S0149-2063(03)00080-1

Jayne, M.E., \& Dipboye, R.L. (2004). Leveraging diversity to improve business performance: Research findings and recommendations for organizations. Human Resource Management, 43(4), 409-424. https://doi.org/10.1002/hrm.20033

Kim, B. (2010). Social constructivism. In M. Orey (Ed.), Emerging perspectives on learning teaching and technology (pp. 55-62). Retrieved from https://textbookequity.org/ Textbooks/Orey_Emergin Perspectives_Learning.pdf

Leininger, M. (2002). Culture care theory: A major contribution to advance transcultural nursing knowledge and practices. Journal of Transcultural Nursing 13(3), 189-192. https://doi.org/10.1177/10459602013003005
Lincoln, Y., \& Guba, E. (1999). Establishing trustworthiness. In A. Bryman \& R.G. Burgess (Eds.). (2002). Qualitative research Vol III (pp. 397-444). London: Sage.

Mounsey, S. (2007). Ethnocentrism and attitudes to cultural diversity and immigration: A review; Ethnocentrism and attitudes to cultural diversity and immigration in Western Australia. Unpublished Honours thesis. Edith Cowan University, Melbourne.

Ocholla, D.N. (2002). Diversity in the library and information workplace: A South African perspective. Library Management, 23(1/2), 59-67. https://doi. org/10.1108/01435120210413850

Patterson, S. (2004). The last trek: A study of the Boer people and the Afrikaner nation. London: Routledge and Kegan Paul Ltd.

Pretorius, M., Cilliers, F., \& May, M. (2012). The Robben Island diversity experience. An exploration of South African diversity dynamics. SA Journal of Industrial Psychology, 38(2), 8. https://doi.org/10.4102/sajip.v38i2.996

Salas, E., \& Cannon-Bowers, J.A. (2001). The science of training: A decade of progress. Annual Review of Psychology, 52, 471-499. https://doi.org/10.1146/annurev. psych.52.1.471

Sandelowski, M. (2000). Whatever happened to qualitative description? Research in Nursing \& Health, 23(4), 334-340. https://doi.org/10.1002/1098-240X(200008) 23:4\%3C334::AID-NUR9\%3E3.0.CO;2-G

Shen, J., Chanda, A., D'netto, B., \& Monga, M. (2009). Managing diversity through human resource management: An international perspective and conceptual framework. The International Journal of Human Resource Management, 20(2), framework. The International Journal of Human Resource

Spreitzer, G.M., Sutcliffe, K.M., Dutton, J.E., Sonenshein, S., \& Grant, G.M. (2005). A socially embedded model of thriving at work. Organization Science, 16, 537-549. https://doi.org/10.1287/orsc.1050.0153

Stevens, F.G., Plaut, V.C., \& Sanchez-Burks, J. (2008). Unlocking the benefits of diversity. All-inclusive multiculturalism and positive organizational change. The Journal of Applied Behavioral Science, 44(1), 116-133. https://doi.org/ 10.1177/0021886308314460

Straub, D., Loch, K., Evaristo, R., Karahanna, E., \& Srite, M. (2002). Toward a theorybased measurement of culture. Human Factors in Information Systems, 10(1) 61-65. https://doi.org/10.4018/978-1-931777-10-0.ch006

Tajfel, H., \& Turner, J.C. (1986). The social identity theory of intergroup behaviour. In S. Worchel \& W.G. Austin (Eds.), Psychology of intergroup relations (pp. 7-24). Chicago, IL: Nelson.

Tajfel, H., \& Turner, J.C. (2004). The social identity theory of intergroup behavior. In J. Jost \& J. Sidanius (Eds.), Political psychology: Key readings (pp. 276-293). New York, NY: Psychology Press.

Thomas, A., \& Bendixen, M. (2000). The management implications of ethnicity in South Africa. Journal of International Business Studies, 31(3), 507-519. https:// doi.org/10.1057/palgrave.jibs.8490919

Thompson, L. (2001). A history of South Africa. New Haven, CT: Yale University Press

Thompson, A., \& Cuseo, J.B. (2009). Diversity and the college experience: Researchbased strategies for appreciating human differences. Kendall Hunt Publishing Company, Dubuque, IA.

Triandis, H.C. (1972). The analysis of subjective culture. New York, NY: Wiley.

Van der Merwe, J.P. (2009). Afrikaner values in post-apartheid South Africa: An anthropological perspective. Doctoral dissertation. University of the Free State, Bloemfontein.

Williams, K., \& O'Reilly, C. (1998). The complexity of diversity: A review of forty years of research. In B. Staw \& R. Sutton (Eds.), Research in organizational behavio (pp. 21, 77-140). Greenwich, CT: JAI Press.

Watts, L. (2009). Managing self in role: Using multiple methodologies to explore selfconstruction and self-governance. In S. Clarke \& P. Hoggett. Researching beneath the surface. psycho- social research methods in practice (pp. 215-239). London: Karnac.

Whitmore, J. (2002). Coaching for performance: Growing people, performance and purpose. London: Nicholas Brealy.

Zulu, P.S., \& Parumasur, S.B. (2009). Employee perceptions of the management of cultural diversity and workplace transformation. SA Journal of Industria Psychology, 35(1), 1-9. https://doi.org/10.4102/sajip.v35i1.426 